\title{
Synthesis, Characterization and Applications of Substituent Naphthalene, Di-arylamine Pendants Based-polyamides, as Semiconductors
}

\author{
AZHAR KAMIL RASHID \\ Department of Chemistry, College of Education for Pure Science/ Ibn Al-Haitham, \\ University of Baghdad, Baghdad, Iraq. \\ ${ }^{*}$ Corresponding author E-mail: azhar_almasody@yahoo.co.uk
}

http://dx.doi.org/10.13005/ojc/340333

(Received: November 05, 2017; Accepted: April 08, 2018)

\begin{abstract}
A new diphenylamine di-acid monomer (4,4'-dicarboxy-6-methylnaphthalene-diphenylamine) (D-COOH) have been synthesized via, aromatic nucleophilic substitution reaction of p-cyanobenzofluride with 5-methoxynaphthalene-1-amine to produce di-cyanide compound (4,4'-dicayno-6-methylnaphthalene-diphenylamine) ( $\mathrm{D}-\mathrm{CN})$, as intermediate then after alkaline hydrolysis of this intermediate to form final di-carboxylic monomer (D-COOH). A series of polyamides $(\mathrm{P}-\mathrm{CONH})$ were synthesized using poly-condensation reaction method with three aromatic diamine compounds (benzidine, 4,4'-methylenedianiline, and 4,4'-oxydianiline). The chemical structures of all result intermediates and polyamides were characterized using FTIR and ${ }^{1} \mathrm{HNMR}$ techniques. All the product polyamides have high solubility in many polar organic solvents, forming thin strong tough films. Polyamides also gave finest thermal stability with height glass transition temperatures $(\mathrm{Tg})$. Solutions of these polyamides in NMP solvent exhibited strong photoluminescence PL. Thin films casting of these polyamides in cyclic voltammetry (C.V) which made from plated glass base of iridium-tin oxide (ITO) as working electrode in dry $\mathrm{CH}_{3} \mathrm{CN}$ solvent contains $0.1 \mathrm{M}$ of tetrabutylantimoneperchlorate (TBAP) as an electrolyte gave one redox wave.
\end{abstract}

Keywords: Cyclic voltammetry, Photoluminescence, Emitting layers, Aromatic diamines compounds.

\section{INTRODUCTION}

Materials with hole-transporting behavior are always an application of the poly light-emitting devices (PLEDs). These polyamides are recognized because of their potential employment in much devices such as lighting sources and displays ${ }^{1,2}$. Polyamides materials are easily convert to ions due to their low ionization potential $\left.\right|^{3-6}$. That mean they can oxidize easily to form stable radical cations ${ }^{7}$. Polyamides have very important applications and advantages as poly light-emitting devices (PLEDs) in the industry. Tri and di-phenylamine based polyamides are usually considered as a hole-transporting part in electronic diodes ${ }^{8-}$ 13. Functional devices of PLEDs are used as 
a thin-plated of an electron transporting and hole-transporting layers are pressed together between two electrodes of different charges ${ }^{14}$. Electrons injected from cathode and holes in the free radical ion (anode) recombine again to emit light ${ }^{15}$. Polyamides molecules that contain amine units show shortage enough emission features because of reductive overcome have been tried for light-emission ${ }^{16}$. The height glass transition $(\mathrm{Tg})$ and melting point (Mp) temperatures properties of aromatic polyamides are known as active polyamide materials resulting from their high mechanical, chemical resistance, thermal stability behaviors ${ }^{17}$. These polyamides are known as having low solubility in more organic solvents, so they need to improve this behavior like insertion of big packing groups into the polyamide chain ${ }^{18-21}$. The polyamides are always prepared via the poly-condensation reaction of di-carboxylic monomers with diamines compounds in the polar organic solvents and $\mathrm{CaCl}_{2}$ as solubility exciter at high temperatures, this method was improved by Yamazaki et al., ${ }^{22}$.

\section{The aim of the work}

In this research, a new series of polyamides $(\mathrm{P}-\mathrm{CONH})$ were synthesized via poly-condensation reaction method with three aromatic diamine compounds (benzidine, 4, 4'-methylenedianiline and 4, 4'-oxydianiline). Electrochemical Properties of all cast films for synthesized polyamides was calculated by cyclic voltammetry (CV).

\section{EXPERIMENTAL}

\section{Materials}

5-methoxynaphthalen-1-amine (fluka, 98.7\%), P-cyanobenzofluoride (Acros, 99.7\%), $\mathrm{N}, \mathrm{N}$-dimethylformamide (Fluka, 99.6\%), Sodium hydride (Merck \& Co. 60\%), potassium hydroxide (fluka, 98.9\%), acetic acid (Merck \& Co. 98\%), Ethanol (Merck \& Co. 98.9\%), Hydrochloric acid
(Merck \& Co. 36\%), Chloroform-D1(Merck \& Co. 99.8\%), dimethyl sulfoxide-D6 (Merck \& Co. 99.7\%), Benzidine (Merck \& Co. 98\%), 4,4'-methylenedianiline (Merck \& Co. 98\%), 4,4'-oxydianiline (Fluka, 98.8\%), Triphenylphosphite (fluka, 99\%), Pyridine (Merck \& Co. 98.9\%), N-methylpyrolidone (NMP) (Fluka, 99.6\%), Calcium chloride (Merck \& Co. 98,9\%).

\section{Apparatus}

UV-Vis abs. and PL spectra were measured in (10-5 M) NMP solvent on a Cary-60 UV-Vis spectrophotometer. Thermogravimetric properties data were recorded with a SDT Q600 thermogravimetric analyzer under nitrogen atmosphere in a rate scan of $20{ }^{\circ} \mathrm{C} / \mathrm{min}$. FT-IR spectrum was restricted with a Spot-light 400 Perkin Elmer spectrometer. ${ }^{1} \mathrm{HNMR}$ data were performed by a JEOL spectrometer.

\section{Monomer Synthesis}

The monomer (D-COOH) was prepared by nucleophilic displacement reaction of $P$-cyanobenzofluoride with aromatic amine 5-methoxynaphthalen-1-amine to produce di-cyanide intermediates (D-CN) as following.

\section{Synthesis of di-cyanide intermediate compound} (4,4'-dicayno-6-methoxynaphthalene-diphenylamine) (D-CN):

Solution of $1.50 \mathrm{~g}(0.02 \mathrm{~mol}) \mathrm{NaH}$ in $70 \mathrm{~mL}$ of DMF was put in (500 round flask) and stirred at room temperature for about 0.5 h. $3.46 \mathrm{~g}$ $(0.02 \mathrm{~mol})$ of 5 -methoxynaphthalen-1-amine, $2.42 \mathrm{~g}(0.02 \mathrm{~mol})$ of $\mathrm{p}$-cyanobenzofluoride were added. The mixture was heated under $120^{\circ} \mathrm{C}$ until $20 \mathrm{~h}$ under nitrogen. After that the cold mixture poured into $180 \mathrm{~mL}$ cold water ${ }^{23}$. Yellowish precipitate was collected by filtration, recrystallized from ethanol and dried. $5.33 \mathrm{~g}$ (yield: $72 \%)$, m. p. $=(179-182) \mathrm{C}^{\circ}$, FT-IR: $2214 \mathrm{~cm}^{-1}$, (CN). ${ }^{1} \mathrm{HNMR}\left(400 \mathrm{MHz}, \mathrm{CDCl}_{3}-\right.$ $\left.\mathrm{d}_{1}, \delta \mathrm{ppm}\right): 8.76(\mathrm{~d}, 1 \mathrm{H}, \mathrm{Hc}), 8.58\left(\mathrm{~d}, 1 \mathrm{H}, \mathrm{H}_{\mathrm{d}}\right), 7.91$ $\left(\mathrm{d}, 4 \mathrm{H}, \mathrm{H}_{\mathrm{a}}\right), 7.48(\mathrm{~d}, 4 \mathrm{H}, \mathrm{Hb}), 6.38\left(\mathrm{~d}, 1 \mathrm{H}, \mathrm{H}_{\mathrm{h}}\right), 3.88$ (s, $3 \mathrm{H}, \mathrm{CH}_{3}$ ).

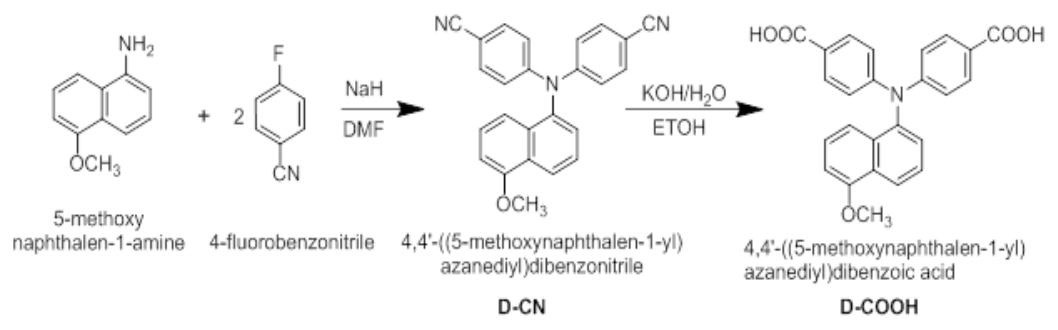

Scheme 1. Synthesis routes of the monomer (D-COOH) 
Synthesis of di-carboxylic monomer (4,4'dicarboxy -6-methoxynaphthalene-diphenylamine(D-COOH )

In $500 \mathrm{ml}$ Becker with stirrer has added $(10.0 \mathrm{~g})$ of $\mathrm{KOH}$ and $7.0 \mathrm{~g}(0.02 \mathrm{~mol})$ of di-cyanide intermediate compound (D-CN) in $70 \mathrm{~mL}$ of $\mathrm{C}_{2} \mathrm{H}_{5} \mathrm{OH}$ and $70 \mathrm{~mL}$ of $\mathrm{H}_{2} \mathrm{O}$ was heated to $110^{\circ} \mathrm{C}$ until all $\mathrm{NH}_{3}$ gas stopped. The needed time for this step was about $24 \mathrm{~h}$ after cooling the solution was neutralized by dilute $\mathrm{HCl}$ to about $\mathrm{pH}=3$ and forming precipitate of yellow color. After filtration washed with water and recrystallized from acetic acid, a pale yellow precipitate was formed, $6.80 \mathrm{~g}(88 \%$ yields $)$ : m.p. $=265-268{ }^{\circ} \mathrm{C} . \mathrm{FTIR}: 1671 \mathrm{~cm}^{-1}(\mathrm{C}=\mathrm{O}), 2982$ $\mathrm{cm}^{-1}(\mathrm{O}-\mathrm{H}) .{ }^{1} \mathrm{H}$ NMR (400 MHz, DMSO-d6, $\delta \mathrm{ppm}$ ): $12.86\left(\mathrm{~s}, 2 \mathrm{H}, \mathrm{C}_{\mathrm{COOH}}\right), 9.25(\mathrm{~d}, 1 \mathrm{H}, \mathrm{Hc}), 8.92(\mathrm{~d}, 4 \mathrm{H}$, $\mathrm{Ha}), 8.26(\mathrm{~d}, 4 \mathrm{H}, \mathrm{Hb}), 6.32\left(\mathrm{~d}, 1 \mathrm{H},\left(\mathrm{H}_{\mathrm{h}}\right), 3.82(\mathrm{~s}, 3 \mathrm{H}\right.$, $\mathrm{CH}_{3}$ ). Scheme-1 displays the synthesis routes of the monomer (D-COOH).

\section{Polyamides Synthesis}

Synthesis of Polyamide (P1-CONH)

$1.65 \mathrm{~g}$ (0.004 mole) of (D-COOH), $1.84 \mathrm{~g}$
(0.01 mol) of benzidine, $1.5 \mathrm{~g}$ of $\mathrm{CaCl}_{2}, 5.0 \mathrm{ml}$ of triphenyl phosphite (TPP), $2.5 \mathrm{ml}$ of pyridine and $5.0 \mathrm{~mL}$ of $\mathrm{N}$-methyl-2-pyrrolidone (NMP) were stirred with heating at $100{ }^{\circ} \mathrm{C}$ until 3 hours. The brown viscous solution was poured slowly into $250 \mathrm{ml}$ beaker containing stirring methanol, forming yellowish fiber precipitate which filtered and washed several times by hot water, followed with methanol and dried at $90{ }^{\circ} \mathrm{C}$ for $24 \mathrm{~h}$., Amide carbonyl band at $1648 \mathrm{~cm}^{-1}$ and (N-H str.) band at $3323 \mathrm{~cm}^{-1}$ are shown by FT-IR spectrum.

\section{Synthesis of Polyamide (P2-CONH)}

This poly polyamide have synthesized by same previous procedure. FT-IR spectrum was $3321 \mathrm{~cm}^{-1}$ of (N-H str.) and $1648 \mathrm{~cm}^{-1}$ of (-C=O amide).

\section{Synthesis of Polyamide (P3-CONH)}

The FT-IR spectrum of this polyamide was $3307 \mathrm{~cm}^{-1}$ of (N-H str.) and $1647 \mathrm{~cm}^{-1}$ of $(-\mathrm{C}=\mathrm{O}$ amide). Scheme 2 shows the polyamides synthesis routes

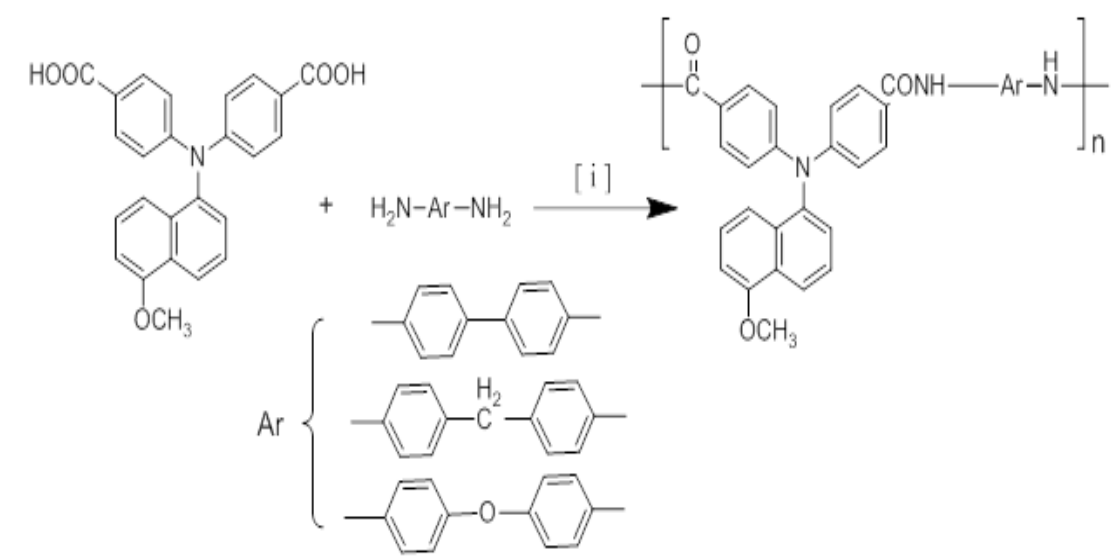

[ i ]: $\mathrm{CaCl}_{2}$ N-methyl-2-pyrrolidone (NMP), pyridine, triphenylphosphite (TPP)

Scheme 2. Method of polyamides synthesis

\section{RESULTS AND DISCUSSION}

\section{Monomer Synthesis}

A new monomers with di-phenylamine-dicarboxylic unites, 4,4'-dicarboxy-6methoxynaphthalene-diphenylamine $(\mathrm{D}-\mathrm{COOH})$ are synthesized by nucleophilic substitution reaction of aromatic mine compound (6-methoxynaphthalene) and $p$-fluorobenzonitrile, followed by basic hydrolysis of di-cyano intermediate (D-CN). The chemical structures of the intermediate (D-CN) and (D-COOH compounds are characterized by FT-IR, ${ }^{1} \mathrm{H}$, and ${ }^{13} \mathrm{C}$ spectroscopic techniques. The FT-IR spectrum band of intermediate, di-cyano compound (D-CN) displayed at $2214 \mathrm{~cm}^{-1}$ ( $\mathrm{C} \equiv \mathrm{N}$ str.). At the end of the hydrolysis process, the di-cyano (D-CN) peak disappeared ,and new appearance of carbonyl absorption band ( $\mathrm{C}=\mathrm{O}$ stretching) at $1671 \mathrm{~cm}^{-1}$ of di-carboxylic acid, in addition, the appearance of broadband at $2982 \mathrm{~cm}^{-1}$ due to (O-H str.), Figure 1. 


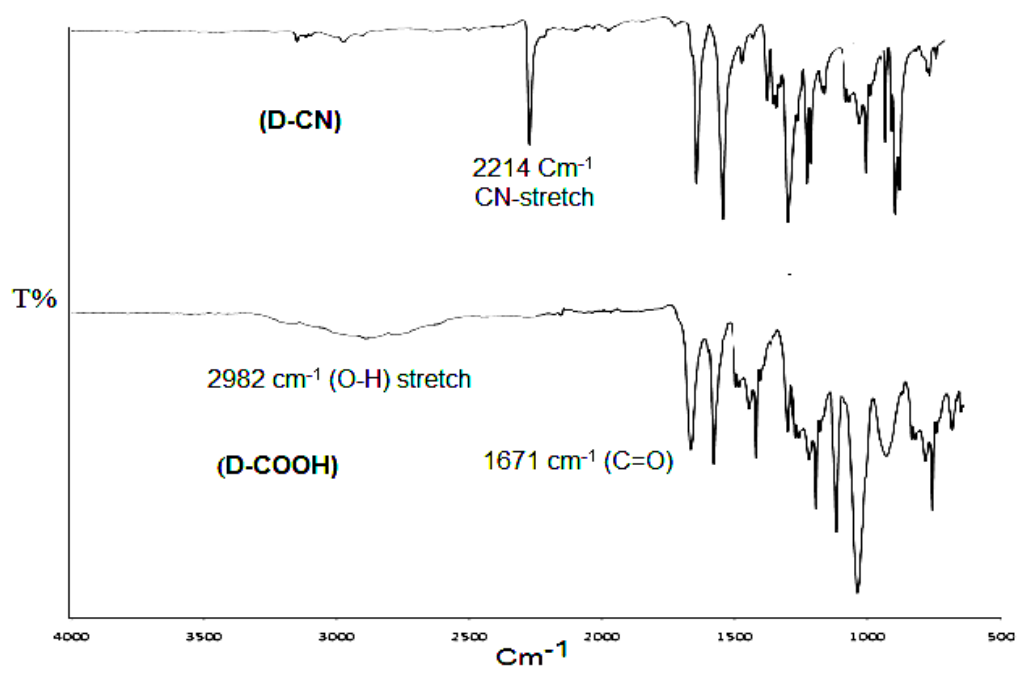

Fig. 1. FTIR of (D-CN) and (D-COOH)

Chemical structures of these compounds were also characterized by ${ }^{1} \mathrm{HNMR}$-spectrum. (D-CN) compound exhibited two main big doublet peaks due to of four protons of $(\mathrm{Ha}): 7.91(\mathrm{~d}, 4 \mathrm{H}$, $\mathrm{Ha})$ and $7.48(\mathrm{~d}, 4 \mathrm{H}, \mathrm{Hb})$ of four protons $(\mathrm{Hb})$. Two doublet peaks of phenylene protons $(\mathrm{Hc})$ at 8.76 $(\mathrm{d}, 1 \mathrm{H}, \mathrm{Hc})$ and $(\mathrm{Hd})$ at $8.58(\mathrm{~d}, 1 \mathrm{H}, \mathrm{Hd})$ in naphthalene. Three protons of methoxy group displayed a singlet peak at $3.88\left(\mathrm{~s}, 3 \mathrm{H}, \mathrm{HCH}_{3}\right)$.

(D-COOH) exhibits small broad peak at 12.86 (br, 2H, CCOOH) attributed to the two $\mathrm{COOH}$ protons,
Also the monomer showed same main two peaks due to four protons (a) and (b) at 8.92 (d, 4H, Ha), $8.26(\mathrm{~d}, 4 \mathrm{H}, \mathrm{Hb})$ respectively. The shifting of these peaks is due to the higher withdrawing of carbonyl group of the carboxylic groups compared with cyano groups. $\mathrm{OCH}_{3}$ group showed singlet peak, attributed to the three protons, displayed as singlet at $3.82 \mathrm{ppm}$. Figure 2.

\section{Polymer Synthesis}

A new aromatic polyamides with di-phenylamines (ADPA) units are prepared by the

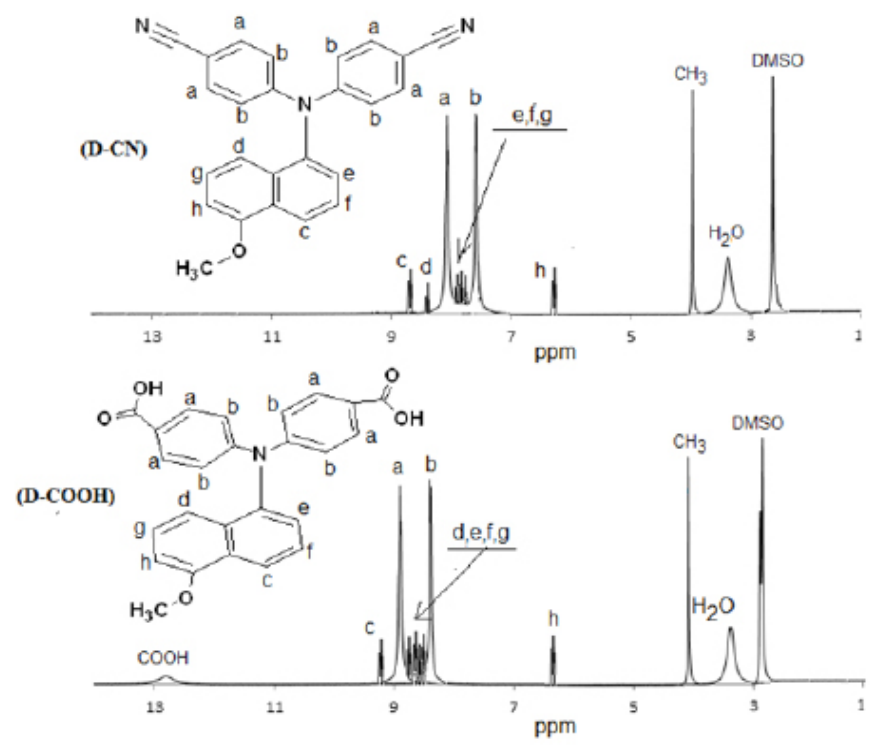

Fig. 2. ${ }^{1} \mathrm{HNMR}$ of (D-CN) and (D-COOH) 
polycondensation reaction of di-carboxylic acid monomer (D-COOH) with many aromatic diamines $\mathrm{H}_{2} \mathrm{~N}-\mathrm{Ar}-\mathrm{NH}_{2}$ (benzidine, 4,4'-methylenedianiline, 4,4'-oxydianiline) using pyridine and triphenylphosphite (TPP) as condensing factors (Scheme 2). The resulting precipitated polyamides were highly viscous solutions in fiber-like form. The hot solution was slowly poured into a baker of stirred methanol. Resulting polyamides can be casted into tough flexible layers. Chemical structure of these polyamides was characterized by FT-IR spectra. The observed bands at $3323(\mathrm{~N}-\mathrm{H}$ str. $)$ and $1648 \mathrm{~cm}^{-1}(\mathrm{C}=\mathrm{O}$ str. of $(\mathrm{NH}-\mathrm{C}=\mathrm{O})$, Figure 3 .

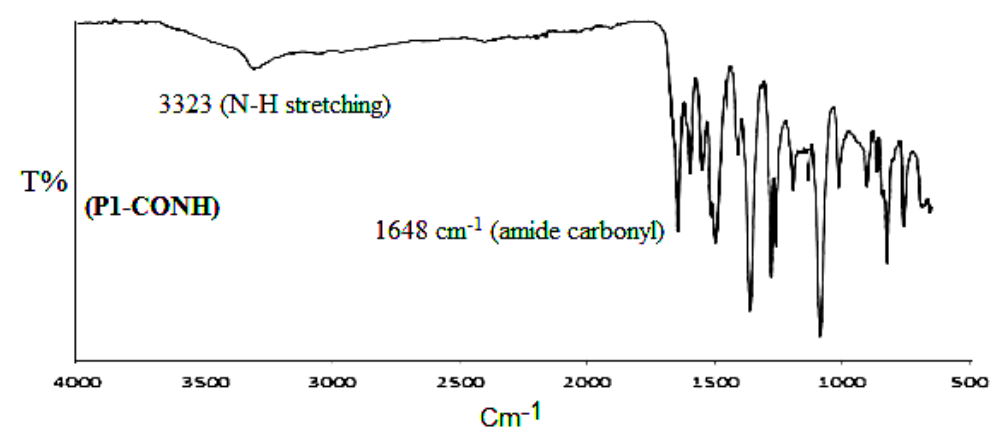

Fig. 3. FTIR of (P1-CONH)

\section{Polymer properties}

\section{(Thermal properties)}

Thermal properties of all synthesized polyamides were inspected using TGA and DSC techniques (the data are outlined in Table 1). All polyamides data exhibited high glass transition temperatures $(\mathrm{Tg})$ between $(258-284){ }^{\circ} \mathrm{C}$, Fig. 4. The $\mathrm{Tg}$ values of these polymers mostly depend on amount of the stiffness of di-amine unite which decrease with decreasing of its stiffness, so polyamides resulting from benzidine diamine showed higher glass transition Tg because of excess of the fact that increasing of rigidity lead to increasing the $\mathrm{Tg}$.

Thermal degradation behavior of all polyamides as shown in TGA curves was carried

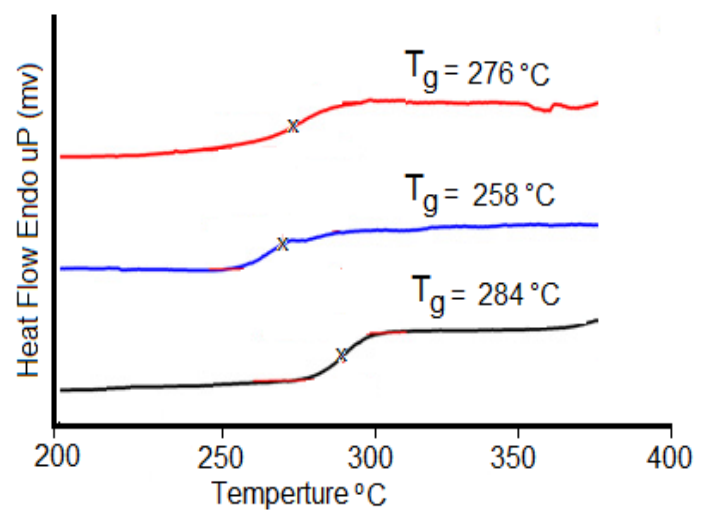

Fig. 4. DSC of synthesized polyamides out at a scan rate of $20^{\circ} \mathrm{C}$ in nitrogen. High thermal stability of all synthesized polyamides with very small weight loss up to $410{ }^{\circ} \mathrm{C}$ and onset weight loss between (256-275) ${ }^{\circ} \mathrm{C}$ attributed to the rigidity of their structure as shown in the order: $(\mathrm{P} 1-\mathrm{CONH})>$ $(\mathrm{P} 2-\mathrm{CONH})>(\mathrm{P} 1-\mathrm{CONH})$ which exhibited that polyamide of benzidine-diamine (P1-CONH) showed the higher thermal stability due to its lower steric space in the chain. The residue weight at $800^{\circ} \mathrm{C}$ for all polyimides was between (17-22) weight percent. At the $10 \%$ weight loss, the temperature for the polyamides was between $(412-520){ }^{\circ} \mathrm{C}$, Figure 5 .

\section{X-ray Diffraction measurements}

The diffraction styles which appear in Fig. 6 explain that the polyamides X-ray diffraction measurements exhibited that all the polyamides were ultimately amorphous.

\section{Spectral properties}

Synthesized polyamides optical properties were measured by UV-Vis spectroscopy. Dilute solutions of these of polyamides in NMP exhibited strong UV-Vis absorption bands at the range (365-394) $n m$ resulting from the $\left(n-\pi^{\star}\right)$ transition because of the nitrogen atoms conjugation with aromatic benzene rings. The $\left(\pi-\pi^{\star}\right)$ characteristic transitions were due to the electronic transitions in the aromatic rings ${ }^{24}$, Figure 7. 


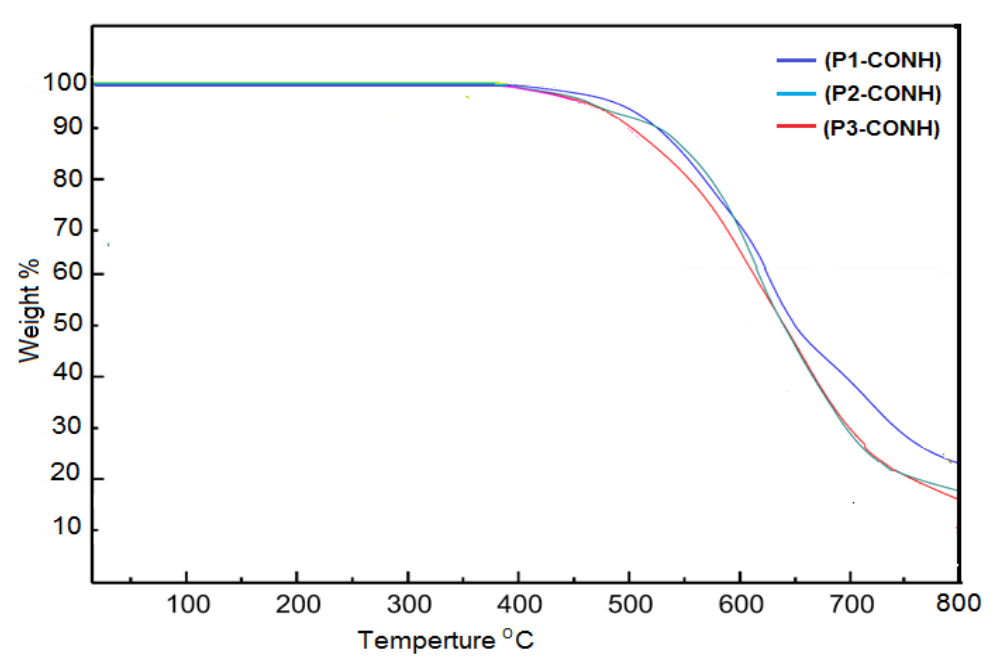

Fig. 5. TGA of synthesized polyamides

Table 1: Thermal behavior of synthesized polyamides

\begin{tabular}{lcccc}
\hline Polyamides & Onset Tg & $\operatorname{Tg}^{\circ} \mathrm{C}$ & 10\% Wt. losss Temp. & Char \% \\
\hline (P1-CONH) & 275 & 284 & 520 & 22 \\
$(\mathrm{P} 2-\mathrm{CONH})$ & 262 & 276 & 464 & 18 \\
$(\mathrm{P} 4-\mathrm{CONH})$ & 256 & 258 & 412 & 17 \\
\hline
\end{tabular}

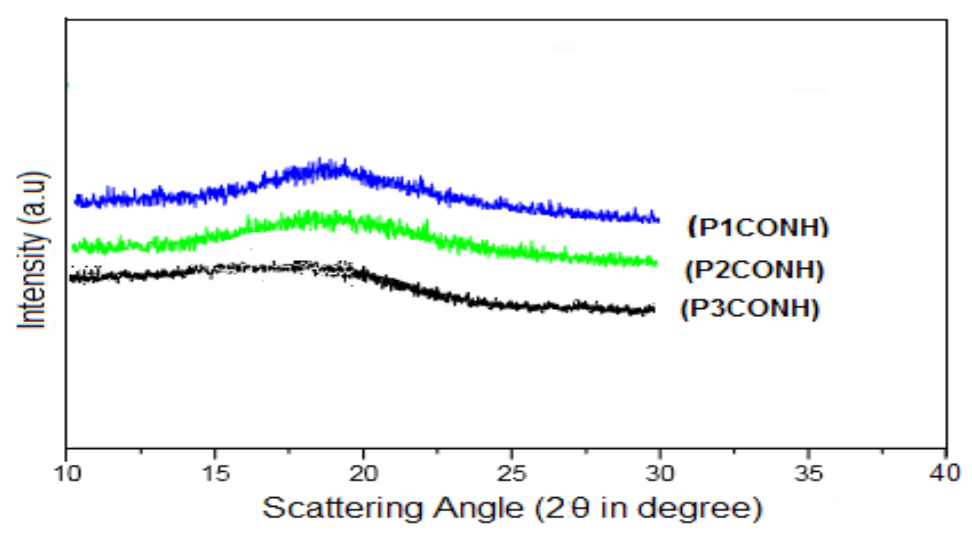

Fig. 6. WAXD patterns of polyamides

\section{Electrochemical Properties}

Electrochemical Properties of all cast films for synthesized polyamides was calculated by cyclic voltammetry (CV) on an ITO-plated glass basis as working electrode in dry $\mathrm{CH}_{3} \mathrm{CN}$ with $0.1 \mathrm{M}$ of tetrabutylammonium perchlorate TBAP to find the HOMO and LUMO energy levels, Fig. 9 (b). The polyamides showed one reversible redox wave. The cyclic voltammogram (CV) of all polyamide samples performed at scan rate of $0.2 \mathrm{~V} / \mathrm{s}$. The energy of the HOMO and LUMO levels of the polyamides are calculated from the UV-Vis wavelength absorption onsets of thin polyamide films and the oxidation (Eonset) 25, the data are outlied in Table 2. The standard Eonset redox of ferrocene/ferrocenium (Fe/Fe+) is $0.41 \mathrm{~V}$ and $\mathrm{HOMO}$ energy of $4.80 \mathrm{eV}$ vs $\mathrm{Ag} / \mathrm{AgCl}$ electrode in $\mathrm{CH}_{3} \mathrm{CN}$ (a). Sample (P1PONH) was an example to explain the steps for calculation of HOMO, LUMO and gap energies for synthesized polyamides as follows: 


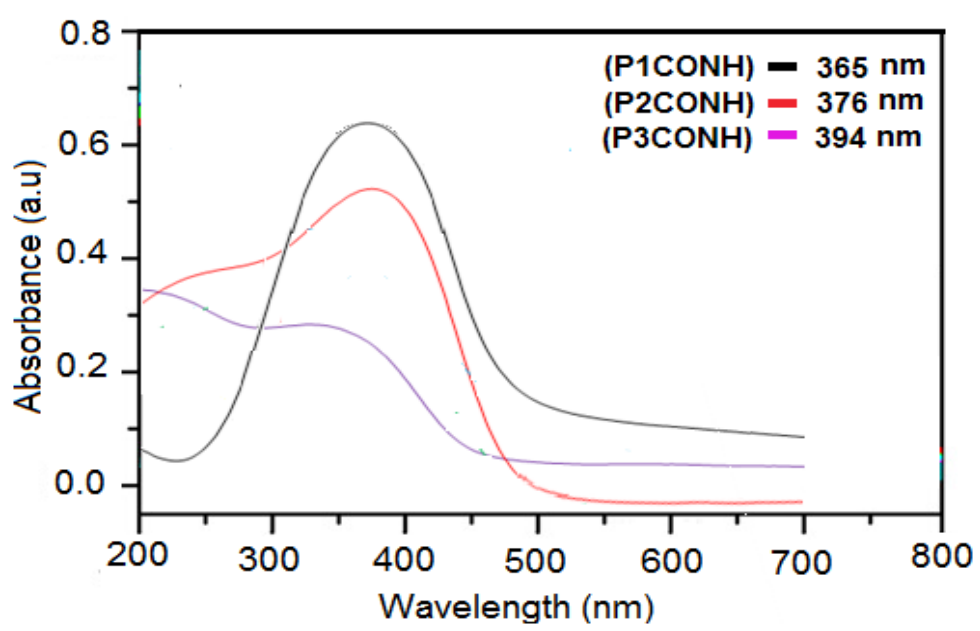

Fig. 7. UV-Vis absorption of synthesized polyamides

Egap $=1241 / \lambda$ abs. onset

Egap $=1241 / 421$

Egap $=2.94 \mathrm{eV}$

Where Eg is Energy gap and 1242 is a constant, $\lambda$ abs. onset is the onset wavelength which can be calculated by intersection of two tangents on the absorption edges of as shown in Figure 8.

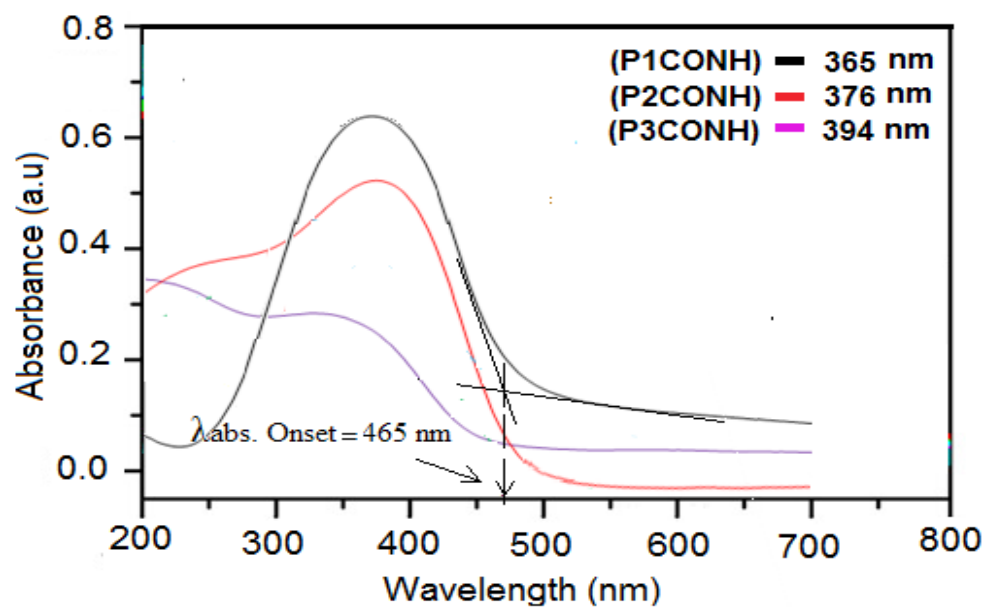

Fig. 8. $\lambda$ abs. onset wavelength OF (P1CONH)

$E_{1 / 2}$ (onset) $=\left(E_{p c}+E_{p a}\right) / 2$ where pc and pa are potential of cathode and anode respectively

$E_{1 / 2}$ (onset) $=\frac{(1.11+0.73)}{2}=0.92 \mathrm{eV}$

$$
\begin{aligned}
& E_{\text {HOMO }} \text { (onset) }=E_{1 / 2} \text { (onset) }-E_{1 / 2} \text { ref. }+4.8 \mathrm{eV} \\
& E_{\text {HOMO }} \text { (onset) }=0.92-0.41+4.8=5.31 \mathrm{eV} \\
& E_{\text {LUMO }} \text { (onset) }=E_{\text {HOMO }} \text { (onset) }-\mathrm{Egap} \mathrm{eV} \\
& E_{\text {LUMO }} \text { (onset) }=5.31 \mathrm{eV}-2.94 \mathrm{eV}=2.37 \mathrm{eV}
\end{aligned}
$$

Table 2: Electrochemical properties of the polyamides

\begin{tabular}{lccccc}
\hline $\begin{array}{l}\text { Polyamides } \\
(\mathrm{nm})\end{array}$ & $\begin{array}{c}\lambda \text { abs. Onset } \\
\text { vs. Ag/AgCl }\end{array}$ & $\begin{array}{c}\mathrm{E}_{1 / 2} \text { (onset) } \\
(\mathrm{ev})\end{array}$ & $\begin{array}{c}\mathrm{E}_{\text {Hомо }} \text { (onset) } \\
(\mathrm{ev})\end{array}$ & $\begin{array}{c}\mathrm{E}_{\text {LUMO }} \text { (onset) } \\
(\mathrm{ev})\end{array}$ & Egap \\
\hline (P1PONH) & 421 & 0.92 & 5.31 & 2.37 & 2.94 \\
(P2PONH) & 418 & 1.01 & 5.40 & 2.44 & 2.96 \\
(P3PONH) & 416 & 1.00 & 5.39 & 2.41 & 2.98 \\
\hline
\end{tabular}




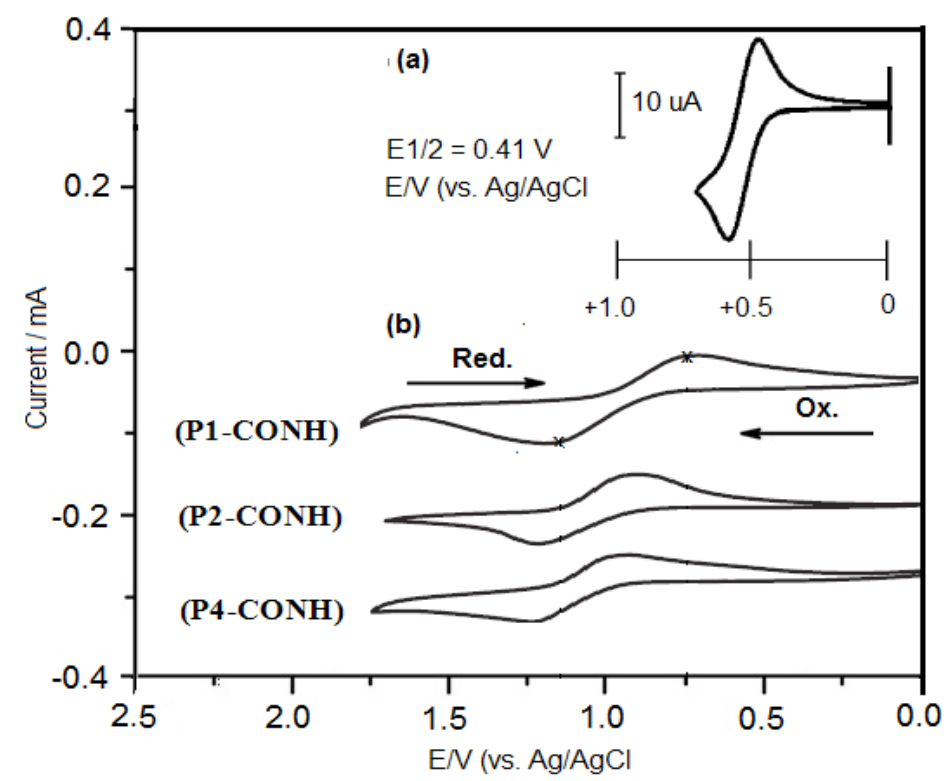

Figure. 9. Cyclic voltammetry for synthesized polyamides

\section{CONCLUSION}

In this study, new polyamides with derived di-phenylamine units were successfully synthesized from reaction of a new aromatic di-phenylamine dicarboxylic acid (D-COOH) with some aromatic diamines by aromatic phosphorylation reaction. All the polyamides were characterized by FT-IR and ${ }^{1}$ HNMR techniques. Thermal, spectral and electrochemistry properties of these polyamides were investigated. They showed high thermal stability and gave useful redox with good color resolution.
The blue photoluminescence behaviors of these polyamides in film and in solution make them can be used in electroluminescent devices as new hole-transporting polyamides.

\section{ACKNOWLEDGEMENT}

I would like to acknowledge department of chemistry, College of Education for pure Science/ Ibn Al-Haitham, University of Baghdad for providing measurements apparatus and chemicals.

\section{REFERENCES}

1. Tang, C.W.; VanSlyke, S.A. Appl. Phys. Lett., 1987, 51, 913.

2. Tang, C.W.; Chen, C.H. J Appl. Phys., 1989. 10. 65,3610

3. Adachi, C.K.; Appl. Phys. Lett.,1995, 66, 2679-2681.

4. Sun, Y.; Maindron, T., Dodelet, J.P.; Iorio, M.D. Chem. Mater., 1999, 11, 2501-2507.

5. Yarn, J.F.; High-performance polymers., New York: Sage Publications., 2008, 120-126,

6. Kulkarni, A.P.; Jenekhe, S.A. J Mater Chem., 2004, 16, 4556-4573.

7. Thelakkat, M.; Schmidt, H.W. Aromatic High-Strength Fibers, New York Wiley., 1989, 71-78.

8. Ogino, K.; Kurtaja, Y.-H. J Macromol Rapid Commun, 1999, 20, 103-106.
9. Chou, M.Y.; Lin, C.C.; Liu, J.H.; Kuo, C.K Chem Mater., 2001, 16, 654-661.

Cheng, S.H.; Liou, G.S., Macromolecules., 2005, 38, 307-316.

11. Hsiao, S.H.; Chen, H.W.; Liou, G.S. J Polym Sci Part A: Polym Chem., 2006, 44, 4579-4592.

12. Beaupre, S.; Leclerc, M.; Chem Mater., 2006, 18, 4011-4018.

13. Choi, K.; Zentel, R. Chem Mater., 2006, 18, 5640-5642.

14. Tang, C.W.; Jianmin, S. Appl Phys Lett., 2002, 80, 3201.

15. Strukelj, M.; Fotis, P.; Miller, T.M.; Rothberg, L. J. AAA Science., 1995, 267, 1969-1972.

16. Mitschke, U.; Bauerle, P. J Mater Chem., 2000, 10, 1471-1507. 
17. Sadava2010rte, N.V.; Avadhani, C.V.; Naik, P.V.; Wadgaonkar, P.P. Eur. Polym. J., 2010, 22. 46, 1307-1315.

18. Imai Y. High Perform Polym., 1995, 7, 337-345.

19. Oishi, Y.; Kakimoto, M. and Imai, Y. J Polym Sci Part A: Polym Chem., 1990, 28, 1763-1769.

20. Liou, G.S.; Kakimoto, M.; Imai, Y. J Polym Sci Part A: Polym Chem., 2002, 40, 2810-2818.

21. Liou, G.S. J Polym Sci Part A: Polym Chem.,
2003, 41, 94-105.

22. Yamazaki, N.; Fukui, H.; Kawataba, J. J Polym Sci olym Chem., 1974, 12, 2149-2154.

23. Liou, G.S.; Yen, H. J. Polym Sci Part A: Polym Chem, 2006, 44, 6094-6102.

24. Oishi, Y.; Kakimoto, M.; Imai, Y. J Polym Sci Part A: Polym Chem., 1990, 28, 1763-1769.

25. Leeuw, D.M.; Einerhand, R.E. Synth Met, 1997, 87, 53-59. 